Federal Reserve Bank of Minneapolis Research Department

\title{
Limited Enforcement and Efficient Interbank Arrangements
}

\author{
Thorsten V. Köppl and James C. MacGee* \\ Working Paper 608
}

January 2001

\begin{abstract}
Banks have historically provided mutual insurance against asset risk, where the insurance arrangement itself was characterized by limited enforcement. This paper shows that a non-trivial interaction between asset and liquidity risk plays a crucial role in shaping optimal banking arrangements in the presence of limited enforcement. We find that liquidity shocks are essential for the provision of insurance against asset shocks, as they mitigate interbank enforcement problems. These enforcement problems generate endogenous aggregate uncertainty as investment allocations depend upon the joint distribution of shocks. Paradoxically, a negative correlation between liquidity and asset shocks ameliorates enforcement limitations and facilitates interbank cooperation.
\end{abstract}

\footnotetext{
*Köppl, University of Minnesota; James C. MacGee, Federal Reserve Bank of Minneapolis and University of Minnesota. We are especially grateful to Narayana Kocherlakota for his encouragement and many discussions. We also thank Beth Allen, V.V. Chari, Tim Kehoe, Igor Livshits, Antoine Martin, Cyril Monnet, Ed Prescott, Michele Tertilt, Warren Weber, Jan Werner and participants of presentations at the University of Minnesota, the Institute for Advanced Studies at the Hebrew University, Jerusalem, and the Midwest Economy Theory Meetings for comments and suggestions. Thorsten V. Köppl acknowledges financial support through NSF grants SBR-9753139 and DMI-9816144 (principal investigator Beth Allen, University of Minnesota). The usual disclaimer applies. The views expressed herein are those of the authors and not necessarily those of the Federal Reserve Bank of Minneapolis or the Federal Reserve System.
} 


\section{Introduction}

There are numerous historic and contemporaneous examples of banks entering into arrangements to provide mutual insurance against asset shocks affecting their assets and liabilities. Surprisingly, many of these interbank insurance arrangements permitted member banks to exit so as to avoid making ex-post insurance transfers to other banks. Even more puzzling, however, is the observation that sometimes ex post transfers between banks did take place, even when the bank making the transfer could have avoided the payment by exiting the arrangement. ${ }^{1}$

These observations lead to the problem of identifying the fundamental factors that are important for the understanding of interbank relationships. Beyond this problem, lies the more imminent question of how these factors interact and whether this interaction is able to explain the specific features of interbank cooperation observed in the examples described above.

In this paper, we advocate two fundamental determinants of interbank relationships, liquidity and default risk that individual banks face. Assuming that arrangements between banks cannot be enforced we show that the interaction between these two forces can account for the empirical examples we have referred to above. This allows us to conclude that - in the absence of a regulatory framework that ensures enforcement - the interaction among banks is driven by risk sharing through a joint exchange of services consisting of liquidity provision and insurance against non-performing asset portfolios.

Our model builds upon a basic investment financing problem. To finance profitable

\footnotetext{
${ }^{1}$ Calomiris (1990) and English (1993) both discuss historic and contemporaneous examples for the United States. Gorton (1985) discusses the behaviour of American clearinghouses in the National Banking era, while Williamson (1989) discusses the evidence for Canadian banking.
} 
projects, borrowers have to seek funds from lenders who are endowed with an investment good, but who do not have direct access to profitable investment opportunities. The relationship between these groups is complicated by the possibility of default by borrowers and stochastic liquidity needs of lenders. Specifically, the repayment of investment funds can only be enforced via the threat of seizure of a risky collateral good with which the borrower is endowed. This feature leads to optimal financing arrangements which feature collateralized debt and nonperforming loans due to strategic default by borrowers ${ }^{2}$.

Preference shocks induce stochastic liquidity needs for lenders. Lenders with liquidity needs will seek to withdraw funds, thereby terminating investment projects prior to completion. Financing on the investor's side will then take the form of a deposit contract. Thus, the possibility of default by borrowers and stochastic liquidity needs of lenders give rise to arrangements which resemble a bank.

To study interactions between banks, we replicate our basic environment and assume that each group of lenders and borrowers are spatially separated ${ }^{3}$. This leads to a lack of exante diversification. Thus, the fundamental force driving bank interaction is a desire to reduce individual risk. Arrangements to share risk, however, have to be self-enforcing: Individual banks are unable to commit and are free to renege ex-post on prior agreements. ${ }^{4}$

In this environment optimal banking arrangements are shaped in a crucial way by the

\footnotetext{
${ }^{2}$ The empirical literature on banking failures has increasingly stressed the importance of shocks to the asset portfolios of banks. Calomiris and Gorton (1991), Calomiris and Mason (1997) and Schumacher (2000), among others, find that banks faced runs and failed as a consequence of sharp declines in asset positions rather than pure liquidity shocks to depositors. Since most of bank intermediated finance takes the form of collateralized debt, we model shocks to a bank's assets as the default of borrowers.

${ }^{3}$ Spatial separation is stressed throughout the banking literature and captures the observation that lending tends to be regionally or functionally specialized and, hence, not fully diversified.

${ }^{4}$ The enforcement friction is introduced into the model to capture the ability of banks to "freely exit" interbank arrangements. On the other hand, limited enforcement between banks allows us to study the basic interaction between the two risk factors abstracting completely from the interference of regulatory institutions.
} 
interaction of liquidity shocks and asset shocks arising from the default risk of borrowers. Optimal contracts feature a form of deposit insurance as an optimal response to weaken the effects of asset shocks on the level of investment. We show that, although liquidity shocks do not provide a motivation for insurance among banks, the provision of liquidity plays an essential role in offsetting enforcement limitations. In the absence of liquidity shocks, limited enforcement implies that banks do not insure one another against collateral shocks. With liquidity shocks, the enforcement problem is partially mitigated, so that banks enter into agreements to insure one another. In other words, the possible exclusion from interbank lending serves as a threat to induce ex post participation in insurance arrangements.

The fact that limited enforcement between banks influences the potential for insurance is not surprising. What is not at first obvious, however, is the critical role that the joint distribution of asset and liquidity shocks plays in determining the extent of insurance. Paradoxically, a negative correlation between liquidity and asset shocks ameliorates enforcement limitations and facilitates cooperation between banks. Moreover, since the level of investment depends upon the joint distribution of shocks, our model endogenously generates aggregate uncertainty. Thus this paper also provides a contribution to the theoretical literature on limited enforcement, as it illustrates how the interaction of purely idiosyncratic shocks in the presence of enforcement limitations can generate aggregate uncertainty.

Our model fuses two distinct strands of the banking literature. A considerable body of work has built upon the seminal contributions of Bryant (1980) and Diamond and Dybvig (1983) and analyzed the implications of stochastic liquidity needs for banking structures. The second branch that we build upon explores the role played by asset risk in banking arrangements. In particular, we closely follow the model of Kocherlakota (1999) and model 
asset shocks as collateral risk to study optimal insurance arrangements related to these shocks.

The theoretical literature on interbank relationships has concentrated mainly on two broad topics. One branch has focused on the benefits of interbank markets in dealing with liquidity shocks, and investigates whether these markets can achieve an optimal diversification of liquidity risk. ${ }^{5}$ The second branch has investigated the potential for contagious effects in the banking sector via links between banks and discusses optimal regulatory responses. ${ }^{6}$

Our paper differs from the existing literature on interbank relationships in several respects. Whereas other models concentrate on particular effects caused by one type of the shocks, we analyze a model where stochastic liquidity needs and asset risk interact in a fundamental way to shape interbank relationships. Moreover, we restrict attention upon the basic trade-off implied by the two sources of risk leaving out informational frictions, and incentive problems such as moral hazard. Finally, our paper links the recent emerging literature on enforcement frictions to the banking literature and, in particular, to the question of interbank relationships.

The paper is organized as follows. The next section sets out the environment, concentrating particularly on the contractual framework and the enforcement frictions. We proceed in section 3 by formally setting up the problem and defining the concept of a contract. Sec-

\footnotetext{
${ }^{5}$ Bhattacharya and Gale (1987) and Bhattacharya and Fulghieri (1994) demonstrate that interbank lending potentially improves welfare, but asymmetric information in this market reduces the sharing of liquidity risk. Chari (1989) shows that well-functioning interbank markets can substantially reduce the risk of bank runs and subsequent bank failures.

${ }^{6}$ Rochet and Tirole (1996) analyze interbank lending with moral hazard and peer monitoring among banks. They discuss optimal central bank policies such as bailouts taking into account possible negative effects on peer monitoring and potential contagious effects arising from interbank lending. In another contribution, Allen and Gale (2000) link organizational aspects of interbank lending markets to the possibility of contagious liquidity shocks. Furthermore, Freixas et. al. (1999) generalize the Diamond and Dybvig (1983) framework to include links across banks caused by spatial relocation of depositors. They identify optimal lending behaviour across banks and discuss whether contagion can occur and what policy responses can prevent this.
} 
tion 4 contains the main analysis: optimal contracts are characterized and the interaction between both types of shocks investigated. Section 5 discusses our results.

\section{The Environment}

The economy consists of $N \geq 3$ identical islands. On each island there is a continuum of two types of agents, denoted as borrowers and lenders, each having unit mass. The economy lasts for a single period divided into three stages labeled $t=0,1,2$.

\section{A. Lenders}

Lenders on each island $i$ are endowed with a single unit of a consumption good and a storage technology yielding a gross return of one. Let $\tilde{\theta}_{i}$ be a random variable with support $\Theta \subset(0,1)$ and denote a realization of $\tilde{\theta}_{i}$ by $\theta_{i}$. Lenders can be of two types: whereas type 1 lenders consume only at $t=1$, lenders of type 2 consume exclusively at $t=2$. Preferences are state-dependent on $\tilde{\theta}_{i}$ where the random variable $\tilde{\theta}_{i}$ represents an island-specific liquidity shock as in Diamond and Dybvig (1983). One can interpret the realization $\theta_{i}\left(1-\theta_{i}\right)$ as the fraction of lenders on island $i$ having to consume at stage $t=1(t=2)$. Formally, preferences of lenders are defined by

$$
u_{L}\left(c_{L, i}^{1}, c_{L, i}^{2} ; \theta_{i}\right)=\left\{\begin{array}{ll}
c_{L, i}^{1} & \text { if type } 1 \text { and realization is } \theta_{i} \\
c_{L, i}^{2} & \text { if type } 2 \text { and realization is } \theta_{i}
\end{array},\right.
$$

where $c_{L, i}^{t}$ is the amount consumed by type $t$ lenders in stage $t$.

Ex-ante preferences are given by $E\left[u_{L}\left(c_{L, i}^{1}, c_{L, i}^{2} ; \theta_{i}\right)\right] \equiv E_{\tilde{\theta}_{i}}\left[\tilde{\theta}_{i} c_{L, i}^{1}+\left(1-\tilde{\theta}_{i}\right) c_{L, i}^{2}\right]$. 


\section{B. Borrowers}

Borrowers are endowed with an investment project and a unit of an indivisible collateral good. To initiate the project an amount $x>0$ of the consumption good must be invested at $t=0$. Projects are of a long-term nature: Once funds are withdrawn from a project, the project is stopped. Therefore, to realize returns from a project, funds have to be continuously invested in the project. The project payoff is given by $\min \{R x, R\}$ units of the consumption good at $t=2$, where $R>1$ is deterministic.

The collateral good is agent-specific: only the specific borrower endowed with the collateral good derives utility from it. Let $\tilde{\nu}$ be a random variable with support $\{0, V\}$, representing a shock to the value of the borrower's collateral good. The distribution of $\tilde{\nu}$ for all borrowers on island $i$ is characterized by the random variable $\tilde{\pi}_{i}$ having support $\Pi \subset(0,1)$, where $\pi_{i}$ is a particular realization of $\tilde{\pi}_{i}$. The realization $\pi_{i}$ is the fraction of borrowers on island $i$ with valuable collateral (i.e. $\nu=V$ ).

Borrowers consume only at stage $t=2$. Preferences are represented by

$$
u_{B}\left(c_{B, i}^{V}, c_{B, i}^{0} ; \pi_{i}\right)=\left\{\begin{array}{ll}
c_{B, i}^{V}+V h & \text { if } \nu=V \text { and realization is } \pi_{i} \\
c_{B, i}^{0} & \text { if } \nu=0 \text { and realization is } \pi_{i}
\end{array},\right.
$$

where $c_{B, i}^{\nu}$ is the amount of the consumption good and $h$ denotes the collateral good consumed by the borrower. We assume that for any realization of $\tilde{\pi}_{i}$ a law of large numbers holds. Ex-ante preferences are then given by $E\left[u_{B}\left(c_{B, i}^{V}, c_{B, i}^{0} ; \pi_{i}\right)\right] \equiv E_{\tilde{\pi}_{i}}\left[\tilde{\pi}_{i}\left(c_{B, i}^{V}+V h\right)+(1-\right.$ $\left.\left.\tilde{\pi}_{i}\right) c_{B, i}^{0}\right]$. 


\section{Uncertainty}

We construct the underlying probability space as an urn experiment. Consider an urn containing $N$ balls each labeled with a different value of $\pi \in(0,1)$. A second urn contains $N$ balls, each labeled with a value of $\theta \in(0,1)$. Let $\Theta=\left\{\theta^{1}, \ldots, \theta^{j}, \ldots, \theta^{N}\right\}$ and $\Pi=\left\{\pi^{1}, \ldots, \pi^{j}, \ldots, \pi^{N}\right\}$ such that $\pi^{1}<\ldots<\pi^{N 7}$. For each island, one ball is drawn independently from each urn without replacement. A realization of the two shocks across islands is a specific assignment of draws from the two urns to the $N$ islands.

Let $S$ denote the set of states of nature. It consists of all possible assignments of $N$ elements of $\Theta$ and the $N$ elements in $\Pi$ to the $N$ islands. A state $s$ is an $N$-vector of ordered pairs $(\pi, \theta)$, where the $i$ th component represents the realization of $\tilde{\theta}_{i}$ and $\tilde{\pi}_{i}$ for island $i$. Formally, $S=\left\{\left(\pi_{i}, \theta_{i}\right)_{i=1}^{N} \mid \pi_{i} \in \Pi, \pi_{i} \neq \pi_{k}, \theta_{i} \in \Theta\right.$, for all $\theta^{j} \in \Theta$, there exists a unique $i$ s.t. $\theta_{i}=$ $\left.\theta^{j}\right\}$. A state $s$ for the economy is thus given by a particular realized joint distribution of both shocks across islands. There are $(N !)^{2}$ elements in $S$. We define a probability measure $\mathcal{U}$ over $S$ by putting equal mass $(1 / N !)^{2}$ on each element of $S$. Then, the probability space $\{S, \mathcal{F}, \mathcal{U}\}$ represents the uncertainty for the economy, where $\mathcal{F}$ is the $\sigma$-algebra consisting of all subsets of $S .^{8}$

\section{Enforceability}

Contracts are subject to several restrictions on enforcement. Lenders have the option of investing their endowment in either the storage technology or the investment project, and of withdrawing their funds from the investment project at $t=1$. Hence, the contract has to

\footnotetext{
${ }^{7}$ Dropping the assumption that the elements of $\Pi$ are different does not alter the results, but does complicate the exposition.

${ }^{8}$ Modeling uncertainty in this fashion simplifies the analysis and allows for a cleaner line of reasoning. All the results of this paper carry over to more general formulations of uncertainty.
} 
insure their participation in the contract at all stages. Second, borrowers on each island have the option of not repaying the lender and consuming the project returns. However, we assume that the collateral good is subject to seizure by the lending side. Therefore, the contracting parties face an ex-post intra-island participation constraint on the borrowing side. Finally, if the contract specifies any inter-island transfers, it must be the case that each island as a whole has an incentive to honor the contract ex-post (inter-island participation). We assume that each island makes its decision on honoring the contract at the beginning of $t=1 .^{9}$

\section{E. Timing}

All information is publicly known by all agents at the stage it is realized. We denote the initial and final investment decision by lenders on island $i$ by $x_{i}^{0}$ and $x_{i}^{1}(s)$, respectively. The time structure of the economy is:

Stage 0:

Lenders and borrowers agree on a contract. Lenders advance $x_{i}^{0}$ to the borrowers on each island.

Stage 1:

For each island, the shocks $\pi_{i}$ and $\theta_{i}$ are realized and each individual lender learns his/her type. While the fraction of borrowers with valuable collateral is known at this stage, the individual realization for each specific borrower is not known. Islands as a whole decide whether to exit the contract. Then, lenders make desired withdrawals $x_{i}^{0}-x_{i}^{1}(s)$ conditional on the realizations of the shocks and consume or store them for consumption in stage 2 .

\footnotetext{
${ }^{9}$ As later analysis will clarify, participation of islands at $t=2$ can always be assured, since inter-island transfers can be secured via forfeiting the right to seize collateral in favor of another island. It is, however, important that the participation decision of the islands is made before all other decisions at date $t=1$.
} 


\section{Stage 2:}

The realization of $\nu$ becomes publicly known for each individual borrower. Borrowers on each island decide whether to walk away or not. Project returns are realized and consumption takes place.

\section{The Contracting Problem}

\section{A. Optimal Contracts}

We study an optimal contracting problem under uncertainty subject to enforcement limitations. Contracts specify state-dependent allocations and investment levels across all $N$ islands and are written before the random variables $\tilde{\pi}_{i}$ and $\tilde{\theta}_{i}$ are realized for each island. The set of possible contracts are constrained by the frictions arising in both the borrower-lender and the inter-island relationships.

Definition 1. An inter-island contract specifies

$$
\begin{aligned}
& \text { investment levels }\left\{x_{i}^{0}, x_{i}^{1}(s)\right\}_{i=1}^{N} \\
& \text { allocations }\left\{c_{B, i}^{V}(s), c_{B, i}^{0}(s), c_{L, i}^{1}(s), c_{L, i}^{2}(s)\right\}_{i=1}^{N} \\
& \text { ownership of collateral for borrowers }\left\{\delta_{i}^{V}(s), \delta_{i}^{0}(s)\right\}_{i=1}^{N} \text {, where } \delta_{i}^{\nu}(s) \in\{0,1\}
\end{aligned}
$$

for all $s \in S$.

The functions $\delta_{i}^{\nu}(s) \in\{0,1\}$ specify whether the borrower retains title to the collateral. If the borrower does not retain title to the collateral good, he cannot consume it in stage 2.

When solving for an optimal inter-island contract we consider a Pareto problem. The objective function assigns all surplus to borrowers, and is given by the summation of the 
borrowers' utility across all $N$ islands ${ }^{10}$ :

$$
E\left[\sum_{i=1}^{N} \pi_{i}\left[c_{B, i}^{V}(s)+\delta_{i}^{V}(s) V\right]+\left(1-\pi_{i}\right) c_{B, i}^{0}(s)\right]
$$

Lenders have the option of withdrawing their funds and utilizing the storage technology. Thus, any contract must satisfy the following two individual rationality constraints for every island $i$ :

$$
c_{L, i}^{1}(s) \geq 1
$$

$$
c_{L, i}^{2}(s) \geq 1
$$

Borrowers on each island also have the option of walking away, albeit at the cost of forfeiting their collateral good. The borrowers participation constraint for stage $t=1$ is:

$$
\pi_{i}\left(c_{B, i}^{V}(s)+\delta_{i}^{V}(s) V\right)+\left(1-\pi_{i}\right) c_{B, i}^{0}(s) \geq R x_{i}^{0}
$$

This constraint compares the expected value of honoring withdrawal requests at stage $t=1$ with the value of continuing investment at the original level. ${ }^{11}$.

There are two different borrower participation constraints - one for each realization of

$\nu$ - in stage $t=2$ :

$$
\begin{aligned}
& c_{B, i}^{V}(s)+\delta_{i}^{V}(s) V \geq R x_{i}^{1}(s) \\
& c_{B, i}^{0}(s) \geq R x_{i}^{1}(s) .
\end{aligned}
$$

\footnotetext{
${ }^{10}$ This problem assumes implicitly that lenders have no bargaining power, which is equivalent to assuming that the lending side is perfectly competitive.

${ }^{11}$ It is clear that lenders would seize collateral in the case of borrowers not honoring the lenders' withdrawal requests, since seizure provides the only penalty for deviation. For notational clarity we do not include this decision in the specification of the constraint, since we will rule out early default by borrowers.
} 
At stage $t=2$, if collateral has value $V$, the borrower weighs the value of consumption under the contract and possible collateral ownership against the possibility of consuming the returns. On the other hand, if borrowers have valueless collateral, they will always choose to default unless the contract offers the entire project return for consumption.

Contracts must satisfy resource feasibility at stages $t=1$ and $t=2$. The resource constraints for each stage are aggregate constraints across islands and, hence, do not have to hold for each island separately:

$$
\begin{aligned}
& \sum_{i=1}^{N} \theta_{i} c_{L, i}^{1}(s) \leq \sum_{i=1}^{N}\left(1-x_{i}^{1}(s)\right) \\
& \quad \sum_{i=1}^{N}\left[\pi_{i} c_{B, i}^{V}(s)+\left(1-\pi_{i}\right) c_{B, i}^{0}(s)\right]+\sum_{i=1}^{N}\left(1-\theta_{i}\right) c_{L, i}^{2}(s) \\
& \leq \quad \sum_{i=1}^{N}\left[R x_{i}^{1}(s)\right]+\left[\sum_{i=1}^{N}\left[\left(1-x_{i}^{1}(s)\right)\right]-\sum_{i=1}^{N} \theta_{i} c_{L, i}^{1}(s)\right] .
\end{aligned}
$$

A key ingredient of our model is the inter-island enforcement restriction. Each island has the ability to not honor the contract at $t=1$ and resort to an autarkic contract. Let $W_{i}^{A}$ be the value of this autarkic contract for island $i$ at stage $t=1$ and denote the value of the contract for island $i$ by $W_{i}^{C}$. The inter-island participation constraint is then given by

$$
W_{i}^{C}(s) \geq W_{i}^{A}(s)
$$

where $W_{i}^{C} \equiv \theta_{i} c_{L, i}^{1}+\left(1-\theta_{i}\right) c_{L, i}^{2}+\pi_{i}\left[c_{B, i}^{V}+\delta_{i}^{V} V\right]+\left(1-\pi_{i}\right) c_{B, i}^{0}$. The final constraints are restrictions on intermediate investment levels

$$
0 \leq x_{i}^{1}(s) \leq x_{i}^{0},
$$


and non-negativity restrictions

$$
c_{B, i}^{\nu}(s) \geq 0,1 \geq x_{i}^{0} \geq 0 \text {. }
$$

Definition 2. An optimal inter-island contract is a contract that solves the following maximization problem $(\mathcal{P} 1)$ :

$$
\max 1 \text { s.to } 7,8 \text { and s.to. 2 - 6, } 9 \text { - } 11 \text { for all islands } i=1, \ldots, N \text {. }
$$

For every island $i$, the autarkic contract is an optimal island-specific contract for the particular island considered. The value of walking away from the inter-island contract, $W_{i}^{A}$, is then given by the sum of consumption allocations specified in the optimal island-specific contract. The next two definitions clarify these concepts.

Definition 3. An island-specific contract for island $i$ is given by

$$
\begin{aligned}
& \text { investment levels } x_{i}^{0}, x_{i}^{1}(s) \\
& \text { allocations } c_{B, i}^{V}(s), c_{B, i}^{0}(s), c_{L, i}^{1}(s), c_{L, i}^{2}(s) \\
& \text { ownership of collateral for borrowers } \delta_{i}^{V}(s), \delta_{i}^{0}(s) \text {, where } \delta_{i}^{\nu}(s) \in\{0,1\} \\
& \text { for all } s \in S \text {. }
\end{aligned}
$$

Definition 4. An optimal island-specific contract for island $i$ is a contract that solves the following maximization problem $(\mathcal{P} 2)$ :

$\max 1$ s.to $2-8,10,11$ for island $i$

where $N=1$.

Finally, it is helpful for our analysis to define a related concept that refers to an optimal inter-island contract where islands do not have the possibility to walk away from the contract 
at $t=1$. We refer to this as the case with full inter-island enforcement, which is essentially the maximization problem $(\mathcal{P} 1)$ without constraint $(9)$. Formally, we have

Definition 5. An optimal inter-island contract with full inter-island enforcement is a contract that solves the following maximization problem $(\mathcal{P} 3)$ :

$\max 1$ s.to 7,8 and s.to. 2 - 6, 10, 11 for all islands $i=1, \ldots, N$.

\section{B. Banks as Optimal Contracts}

The optimal contract characterized in the next section captures several key features which are associated in the theoretical literature with the institution of a bank. It explicitly contains both a deposit contract and a debt contract feature. The deposit contract feature arises from the fact that any optimal contract includes initial investment for all lenders with the option to withdraw funds at later stages. This withdrawal can be made for two reasons: either to meet the personal liquidity needs of lenders or to liquidate investment on the island in response to information about negative asset shocks. ${ }^{12}$ The asset side of the contract resembles collateralized debt ${ }^{13}$.

We interpret the optimal contract as an optimal banking arrangement where the contract specification for each island is identified as an individual bank. Banks are island-specific and possible inter-island transfers occur between island-specific banks. The inter-island enforcement restriction, equation 9, is interpreted as the ability of individual banks to exit

\footnotetext{
${ }^{12}$ The formulation of the participation constraints rules out suspension schemes for banks. Therefore, the contract has not only a deposit but also a demandable debt feature. Calomiris and Kahn (1991) emphasize that demandable debt is the crucial feature that characterizes banks. They also provide evidence that suspension schemes were only used by the banking system as a whole, but not by individual banks, thus empirically supporting this particular feature.

${ }^{13}$ Although the debt feature of the contract is not obvious, a simple and for our purposes inessential extension would make this feature explicit. Kocherlakota (1998) uses asymmetric information with respect to the collateral value to generate more clearly simple debt as the optimal contract.
} 
interbank arrangements. To be able to identify specifics of these interbank arrangements further, we define two concepts, deposit insurance and interbank lending.

Definition 6. A deposit insurance system is a transfer scheme $\left\{T_{i}\right\}_{i=1}^{N}, T_{i}: S \longrightarrow \mathbb{R}$, for all $i=1,2, \ldots, N$ s.th.

1. $\exists \hat{\pi} \in[0,1]$, s.th. $T_{i} \geq 0$ for $\pi_{i}<\hat{\pi}$ and $T_{i}<0$ for some $\pi_{i}>\hat{\pi}$

2. $\sum_{i=1}^{N} T_{i} \geq 0$.

Deposit insurance systems involve transfers from solvent to insolvent banks subject to feasibility restrictions. In our framework the parameter $\hat{\pi}$ plays the role of determining solvency of banks. The first feature of our transfer scheme captures the essential nature of deposit insurance, whereas the second one refers to a feasibility restriction: Net transfers between banks have to be non-negative, which rules out systems that depend on the provision of funds to the banking system from outside such as bail-outs. Moreover, the transfer system has to satisfy all the enforcement and feasibility constraints of the inter-island contracting problems, since deposit insurance is analyzed here as a particular feature of optimal contracts between banks.

Definition 7. A contract features interbank lending if $\exists i$ s.th. $x_{i}^{1}(s)>1-\theta_{i}$ for some $i=1, \ldots, N$.

Our definition refers to the feature of one bank freeing up funds to provide liquidity to another bank. This enables the bank receiving the funds to maintain the original investment level and to avoid termination of some of its projects due to liquidity demand by lenders. Hence, it formalizes the occurrence of short-term lending between banks to obtain liquidity. 


\section{Optimal Contracts}

\section{A. Optimal Island-Specific Contracts}

We begin our analysis of efficient arrangements among islands by studying the benchmark case of the autarkic contract for a single island. This problem is of use both in specifying the value of the walk away option islands have and in understanding the driving forces in inter-island contracts. Prior to characterizing the optimal contract, we introduce the following assumption which we maintain throughout the paper. All proofs are given in the appendix.

Assumption 1. $\min _{\pi_{i} \in \Pi} \pi_{i} V \geq R$.

Lemma 1. Suppose Assumption 1. holds and $\delta_{i}^{V}(s)=1$ for all $i=1, \ldots, N$. Then, any optimal contract specifies $x_{i}^{0}=1$.

Assumption 1. simplifies the analysis considerably and avoids the problem that it might be optimal for lenders not to invest at all at stage $t=0^{14}$. It implies that the expected cost of defaulting at stage $t=1$ exceeds the expected gain. Lemma 1 . thus implies that all liquidation requests by lenders at $t=1$ will be honored.

At $t=0$, lenders and borrowers on the island agree on a contract that takes into account only the possible realizations of the shock on their island. The optimal investment and consumption levels are characterized as follows.

\footnotetext{
${ }^{14}$ This assumption is equivalent to allowing for contracts that specify only final investment levels for stage $t=1$, but do so at the contracting stage $t=0$ without handing over the investment funds. Projects are then initiated as soon as borrowers receive the investment. We, however, chose the more general formulation to generate a basic deposit feature within the contract which enables us to interpret our results in light of the literature on banking. Early commitment of funds without actual physical investment taking place is a common feature of many projects. An example from the banking sector would be the provision of credit lines or the declaration of an intention to fund a particular project which ties at least partially the funds to the project in question.
} 
Proposition 1. An optimal island-specific contract for island $i$ specifies investment levels

$$
x_{i}^{1}(s)=\left\{\begin{array}{ll}
1-\theta_{i} & \text { if } \pi_{i} \geq \bar{\pi} \\
0 & \text { if } \pi_{i}<\bar{\pi}
\end{array},\right.
$$

where $\bar{\pi}=1 / R$.

Corollary 1. Optimal consumption levels for island $i$ are given by

$$
\begin{aligned}
& c_{L, i}^{t}(s)=1 \text { for } t=1,2, \\
& c_{B, i}^{V}(s)= \begin{cases}\frac{1}{\pi_{i}}\left(1-\theta_{i}\right)\left(\pi_{i} R-1\right) & \text { if } \pi_{i} \geq \bar{\pi} \\
0 & \text { if } \pi_{i}<\bar{\pi}\end{cases}
\end{aligned}
$$

and

$$
c_{B, i}^{0}(s)=\left\{\begin{array}{ll}
R\left(1-\theta_{i}\right) & \text { if } \pi_{i} \geq \bar{\pi} \\
0 & \text { if } \pi_{i}<\bar{\pi}
\end{array} .\right.
$$

The investment allocations specified above help to illustrate one of the driving forces of the model. The realized value of the collateral shock determines whether or not lenders leave their funds in the investment project, or choose to liquidate the bank. This decision is characterized by a cut-off rule: if the collateral shock is not too bad (i.e. $\pi_{i}>\bar{\pi}$ ), funds are only withdrawn for liquidity purposes. All remaining funds stay invested at date $t=1$. However, if there is a bad realization of the collateral shock, all funds are withdrawn and liquidation occurs. This outcome is socially suboptimal in the sense that projects which are terminated would yield a higher rate of return than the storage technology.

Corollary 2. For $\max _{\theta_{i} \in \Theta} \theta_{i} \rightarrow 0, x_{i}^{1}(s) \rightarrow 1$ for all $\pi_{i} \geq \bar{\pi}$. 
It is worth emphasizing that, in the island-specific contract, the interaction between liquidity and asset shocks is trivial. As Corollary 2. shows, liquidity shocks do not directly aggravate the detrimental nature of these factors, but indirectly influence the amount of funds available for investment projects. Liquidity shocks provide a mere scaling effect that reflects the influence of withdrawals to satisfy consumption for early lenders. The liquidation decision at $t=1$ is independent of $\theta_{i}$, and depends only the realization of the asset shock $\pi_{i}$. However, liquidity shocks, by reducing investment, lead to lower output and consumption by borrowers.

\section{B. Optimal Inter-Island Contracts with Full Enforcement}

We proceed now by characterizing the optimal contract with full inter-island enforcement. To simplify notation we define three constant integers, $M, L$ and $K$. The constant $M$ specifies the number of islands having a realization of $\pi_{i} \geq \bar{\pi}$. The integer $L$ stands for the overall liquidity needs in the economy. Finally, $K$ will summarize the maximal extent of insurance against the asset shock in the absence of liquidity needs. Its definition relies on the fact that project returns can only be extracted - and used for transfers - from borrowers with valuable collateral. $^{15}$

Assumption 2. Let $\pi_{1}<\ldots<\pi_{N}{ }^{16}$. Assume there exist $M, L$, and $K \in \mathbb{N}$ s.th.

1. $M=\#\left\{\pi_{i} \mid \pi_{i} R \geq 1\right\}$

2. $L=E\left(\theta_{i}\right) N=\sum_{i=1}^{N} \theta_{i}$

\footnotetext{
${ }^{15}$ Constraints (2) and (3) imply that lenders must receive at least their initial endowment, while - by constraint $(6)$ - no funds can be extracted from borrowers with a realization of $\nu=0$. Hence, funds can be extracted only from borrowers with valuable collateral.

${ }^{16}$ This assumption is innocuous, as the optimal contract is anonymous in that it does not depend upon which island receives which pair of shocks $\left(\pi^{j}, \theta^{k}\right)$, and simplifies the presentation of our analysis.
} 
3. $\sum_{\{i \mid i>K\}}\left(\pi_{i} R-1\right)=0$.

Proposition 2. The investment levels at $t=1$ for the optimal contract with full inter-island enforcement depend on $E\left(\theta_{i}\right)$ and the distribution of $\left\{\pi_{i}\right\}_{i=1}^{N}$, but are independent of the state $s$.

The optimal total investment level is given by $\sum_{i=1}^{N} x_{i}^{1}(s)=N-\max \{K, L\}$ and final investment on the individual islands is characterized by

$$
\begin{aligned}
& \text { Case(i): } K \geq L \\
& x_{i}^{1}(s)= \begin{cases}1 \quad \text { if } \pi_{i}>\pi_{K} \\
0 \quad \text { if } \pi_{i} \leq \pi_{K}\end{cases}
\end{aligned}
$$

Case(ii): $L>K$

$$
\sum_{i=1}^{N}\left[\left(\pi_{i} R-1\right) x_{i}^{1}(s)\right] \geq 0
$$

Corollary 3 . If $K \geq L$ every optimal inter-island contract with full inter-island enforcement features interbank lending and deposit insurance. If $L>K$, optimal inter-island contract feature interbank lending or deposit insurance, or both.

Proposition 2. specifies the extent to which the economy is able to achieve full investment of all resources after accounting for liquidity needs. Since total welfare is strictly increasing in the number of projects funded, it is (socially) optimal to fund as many projects as possible. Case (ii) of the proposition considers situations where liquidity needs are extremely high. Here, insurance against asset shocks interferes with liquidity provision. While the optimal investment allocations are not unique, the aggregate investment level is unique 
and is determined solely by overall liquidity needs. For case (i) liquidity shocks are not so extreme as to interfere with insurance against asset shocks. In this case, it is optimal to liquidate islands with the worst collateral shocks first to pay the early withdrawers. This allows one to continue all investment projects on islands with the most favorable collateral shock or, equivalently, with the highest return that can be extracted on average from borrowers. A maximum amount of transfers is then available to subsidize projects on other islands that would otherwise not have been undertaken.

For both cases, only the distribution of collateral shocks across islands is important for the allocation of investment funds. Corollary 3. emphasizes the key advantages of an aggregate contract including all islands: One is able to transfer resources from islands with high collateral values to islands with bad realizations of the collateral shock independent of the realizations of the liquidity shock. Hence, the economy is not exposed to aggregate uncertainty, since the overall investment levels do not depend on the joint distribution of the shocks.

Interbank lending is an essential feature of the contract, as it allows the insurance scheme to operate independently of the distribution of liquidity shocks across islands. Without this feature, an insurance scheme would have to take into account that islands are hit by different liquidity shocks, potentially reducing the magnitude of insurance.

Corollary 4. For $\max _{\theta_{i} \in \Theta} \theta_{i} \rightarrow 0, x_{i}^{1}(s) \rightarrow 1$ for all $i$ s.th. $\pi_{i}>\pi_{K}$.

As in the island-specific contract, there is a trivial interaction between liquidity and collateral shocks. Liquidity shocks per se are inessential for the possibility of deposit insurance, and their realized value merely influences the aggregate level of investment. Corollary 4. 
shows that, as liquidity needs approach 0 , insurance against collateral shocks is not affected. In the next section we demonstrate that with limited enforcement between islands, not only the joint distribution of both shocks matters, but also that the presence of liquidity shocks are imperative for the feasibility of deposit insurance.

\section{Optimal Inter-Island Contracts}

In the presence of limited inter-island enforcement, individual islands will honor the contract only if they receive at least the ex-post value of autarky. Islands with realizations of $\pi_{i}$ such that $\pi_{i} R<1$ always find it optimal to stay within the contractual arrangement, as any contract implicitly specifies non-negative transfers for these islands. For all other islands, however, the ex-post participation constraint cannot be neglected.

Suppose an inter-island contract sets $x_{i}^{0}=1$ for each island. If an island $i$ with $\pi_{i} R \geq 1$ exits an inter-island contract at stage $t=1$ before withdrawals are announced, the best it can do on its own is to implement the optimal island-specific contract as of stage $t=1$. Thus, given $x_{i}^{0}=1$, the value of autarky $W_{i}^{A}(s)$ for this island is the overall value of the optimal island-specific contract or

$$
R\left(1-\theta_{i}\right)+\theta_{i}+V \pi_{i}
$$

Whenever an optimal inter-island contract involves deposit insurance, only borrowers with valuable collateral can be taxed to finance the transfer scheme. Using Corollary 1., overall utility for these borrowers after transfers is given by

$$
\pi_{i}\left(c_{B, i}^{V}(s)+V\right)=\left(\pi_{i} R-1\right) x_{i}^{1}(s)+T_{i}(s)+\pi_{i} V,
$$

where $T_{i}(\cdot)$ is the total transfer extracted from island $i$. The value of an optimal 
inter-island contract $W_{i}^{C}$ is then given by

$$
1+\left(\pi_{i} R-1\right) x_{i}^{1}(s)+T_{i}(s)+\pi_{i} V+R\left(1-\pi_{i}\right) x_{i}^{1}(s)
$$

or

$$
\left(1-x_{i}^{1}(s)\right)+R x_{i}^{1}(s)+T_{i}(s)+\pi_{i} V .
$$

Using equations (12) and (14), the inter-island enforcement constraint (9) can be rewritten as

$$
-T_{i}(s) \leq \theta_{i}(R-1)+\left(x_{i}^{1}(s)-1\right)(R-1) .
$$

The extent of deposit insurance is also limited by the fact that enforcement of the contract with each borrower on each island is also limited. This implies that no more than $x_{i}^{1}(s)\left(\pi_{i} R-\right.$ $1) / \pi_{i}$ per borrower with valuable collateral can be extracted. The next lemma characterizes the ex-post inter-island participation constraint 9 in terms of the feasible transfer $T_{i}(\cdot)$ that can be implicitly imposed by an optimal inter-island contract.

Lemma 2. Deposit insurance is feasible for an inter-island contract, if it satisfies

$$
-T_{i}(s) \leq \min \left\{\theta_{i}(R-1)+\left(x_{i}^{1}(s)-1\right)(R-1),\left(\pi_{i} R-1\right) x_{i}^{1}(s)\right\}
$$

for any $i$ s.th. $\pi_{i}>\bar{\pi}$ and $T_{i}(s) \geq 0$ otherwise.

The next result characterizes total investment for the optimal inter-island contract in the presence of enforcement problems among islands.

Proposition 3. The investment functions at $t=1$ for the optimal inter-island contract depend on $E\left(\theta_{i}\right)$ and the joint distribution $s$. 
Specifically, the optimal total investment level at $t=1$ is characterized by

$$
\sum_{i=1}^{N} x_{i}^{1}(s) \leq N-L
$$

The Proposition illustrates how three factors influence the optimal inter-island contract: the overall size of liquidity needs in the economy; the importance of liquidity needs relative to collateral risk; and the specific realization of the state $s$. Limited enforcement among islands potentially reduces total investment. Whenever it reduces total investment, as demonstrated below, overall liquidity needs are not too high and the joint distribution of shocks across islands prohibits the extraction of maximal transfers from islands with favorable asset shocks. We proceed by first analyzing the situation when overall liquidity needs do not interfere per se with the potential of deposit insurance, i.e. $K \geq L$. Then, we contrast these result with the situation of high overall liquidity needs.

Proposition 4. Let $K \geq L$. Define $\bar{T}_{i}(s)=(-1) \min \left\{\theta_{i}(R-1),\left(\pi_{i} R-1\right)\right\}$. Investment on individual islands at $t=1$ is uniquely characterized by

$$
x_{i}^{1}(s)=\left\{\begin{array}{ll}
1 & \text { if } \pi_{i}>\tilde{\pi} \\
\tilde{x} & \text { if } \pi_{i}=\tilde{\pi}, \\
0 & \text { if } \pi_{i}<\tilde{\pi}
\end{array},\right.
$$

s.th. $\bar{\pi} \geq \tilde{\pi} \geq \pi_{K}$ and $\tilde{x} \in[0,1]$ are unique and satisfy

$$
\sum_{i>K}^{N-M}\left[\left(\pi_{i} R-1\right) x_{i}^{1}(s)\right]=\sum_{i>N-M}^{N} \bar{T}_{i}(s) .
$$

Furthermore, $\sum_{i=1}^{N} x_{i}^{1}(s)<N-L$ iff $\theta_{i}<\frac{\pi_{i} R-1}{R-1}$ for some $i$ such that $\pi_{i}>\bar{\pi}$.

Proposition 5. Let $L>K$. Define $\bar{T}_{i}(s)=(-1) \min \left\{\theta_{i}(R-1),\left(\pi_{i} R-1\right)\right\}$. 
1. Suppose $\sum_{i>N-M}^{N} \bar{T}_{i}(s) \leq \sum_{i>L}^{N-M}\left(\pi_{i} R-1\right)$. Then, $\sum_{i=1}^{N} x_{i}^{1}(s)=N-L$. Furthermore, any investment functions $\left\{x_{i}^{1}(s)\right\}_{i=1}^{N}$ with $\sum_{i=1}^{N} x_{i}^{1}(s)=N-L$, s.th. given $\left\{x_{i}^{1}(s)\right\}_{i=1}^{N}$ there exists a feasible $\left\{T_{i}\right\}_{i=1}^{N}$ satisfying

$$
\sum_{i=1}^{N-M}\left[\left(\pi_{i} R-1\right) x_{i}^{1}(s)\right]=\sum_{i>N-M}^{N} T_{i}(s),
$$

are optimal.

2. Suppose $\sum_{i>N-M}^{N} \bar{T}_{i}(s)>\sum_{i>L}^{N-M}\left(\pi_{i} R-1\right)$. Then, investment on individual islands at $t=1$ is uniquely characterized by the investment functions of Proposition 4., where $\pi_{K}$ is replaced by $\pi_{L}$ and $K$ is replaced by $L$ in condition 16. Furthermore, $\sum_{i=1}^{N} x_{i}^{1}(s)<$ $N-L$ and there is an island $i$ s.th. $\theta_{i}<\frac{\pi_{i} R-1}{R-1}$ and $\pi_{i}>\bar{\pi}$.

In the case of low liquidity needs $(K \geq L)$, the distribution of asset shocks still determines which islands keep their funds invested. Furthermore, the optimal contract again separates the means for liquidity provision and insurance against asset shocks. Unlike in Proposition 2. the cut-off point for investment at $t=1$, however, depends now on the joint distribution of shocks. If for some island $i$ with $\pi_{i}>\bar{\pi}$ the liquidity shock is too small relative to the collateral shock, the island has an incentive to leave any contract that imposes transfer payments that are too high. Hence, overall transfers to islands with adverse collateral shocks are too small to achieve full investment. The unique cut-off point and, hence, the total amount of investment depends on the maximal transfer compatible with inter-island enforcement, which in turn is a function of the state $s$. Aggregate uncertainty arises endogenously through the enforcement limitations between islands, even though the economy as a whole is not exposed to uncertainty with respect to either the asset shocks or the liquidity shocks separately. 
For $L>K$ all results remain qualitatively the same. The only difference is an indeterminacy of how funds get invested across islands whenever maximal transfers are feasible.

Corollary 5 . If $K \geq L$ the optimal inter-island contract features interbank lending and deposit insurance. Otherwise, any optimal inter-island contract features interbank lending or deposit insurance or both.

Corollary 6. If $\max _{\theta_{i} \in \Theta} \theta_{i} \rightarrow 0, x_{i}^{1}(s) \rightarrow 0$ for all $i$ s.th. $\pi_{i}<\bar{\pi}$.

Corollary 7. For any $\pi_{i} \geq \bar{\pi}, \frac{\partial\left|\bar{T}_{i}\right|}{\partial \theta_{i}} \geq 0$ where $\bar{T}_{i}(s)=(-1) \min \left\{\theta_{i}(R-1),\left(\pi_{i} R-1\right)\right\}$. Furthermore, suppose $\theta_{i} \geq \frac{\pi_{i} R-1}{R-1}$ for all $\pi_{i}>\bar{\pi}$. Then, investment at $t=1$ for any optimal inter-island contract satisfies Equation 15 with equality.

Corollaries 5. to 7. demonstrate that liquidity shocks serve as a "threat point" to keep islands from leaving the contract. As long as there are strictly positive liquidity shocks some insurance against collateral shocks is in principle possible even if enforcement among islands is limited. In the absence of liquidity shocks $-\theta_{i}=0$ for all $i$-,however, limited enforcement among islands results in zero inter-island transfers: $\bar{T}_{i}=0$ for all $i$ and feasible $\left\{x_{i}^{1}(s)\right\}_{i=1}^{N}$.

This stands in sharp contrast to Corollary 4.. If full enforcement between islands can be guaranteed, liquidity needs are inessential for the feasibility of deposit insurance. Here one can always extract all surplus from borrowers with valuable collateral and, hence, the maximum amount of transfers can achieve full investment for all $i$ s.th. $\pi_{i}>\pi_{K}$ independent of the liquidity shock.

Paradoxically, if inter-island enforcement is limited, a negative correlation between both shocks helps to increase investment. The higher the liquidity needs on islands with 
good collateral shocks, the more transfers are available for deposit insurance. Thus, once again, the joint distribution of both shocks is the crucial element in determining overall investment at $t=1$. Provided liquidity is high enough on all islands with $\pi_{i} \geq \bar{\pi}$, optimal contracts with and without full inter-island enforcement coincide.

\section{Example}

The theoretical analysis developed two key results: Liquidity needs are crucial to support ex post insurance transfers and the joint distribution of shocks determines the exact structure of the optimal contract. To illustrate the importance of liquidity needs we consider an example where all islands receive the same liquidity shock. Later, we will modify the example and allow for island-specific differences in the liquidity shock to study the importance of the joint distribution.

Suppose that $N=3, R=1.4, \Pi=\{0.8,0.65,0.5\}$ and $\Theta=\{a, a, a\}$ where $a \in$ $\{0,0.1,0.3\}$. These parameters are chosen such that the overall liquidity needs do not interfere with the general feasibility of deposit insurance. The next table describes the efficient investment allocations and transfer schemes for every aggregate liquidity level. 


\begin{tabular}{|c|c|c|c|}
\hline & $i=1$ & $i=2$ & $i=3$ \\
\hline & $\pi_{1}=0.8$ & $\pi_{2}=0.65$ & $\pi_{3}=0.5$ \\
& $\pi_{1} R=1.12$ & $\pi_{2} R=0.91$ & $\pi_{3} R=0.7$ \\
\hline Inter - Island & $x_{1}^{1}(\cdot)=1$ & $x_{2}^{1}(\cdot)=1$ & $x_{3}^{1}(\cdot)=0.1$ \\
Full Enforcement & $T_{1}=-0.12$ & $T_{2}=0.09$ & $T_{3}=0.03$ \\
\hline Inter-Island & & & \\
No Enforcement & & & \\
\hline & $x_{1}^{1}(\cdot)=1$ & $x_{2}^{1}(\cdot)=0$ & $x_{3}^{1}(\cdot)=0$ \\
$\Theta=\{0,0,0\}$ & $T_{1}=0$ & $T_{2}=0$ & $T_{3}=0$ \\
\hline & $x_{1}^{1}(\cdot)=1$ & $x_{2}^{1}(\cdot)=0.44$ & $x_{3}^{1}(\cdot)=0$ \\
$\Theta=\{0.1,0.1,0.1\}$ & $T_{1}=-0.04$ & $T_{2}=0.04$ & $T_{3}=0$ \\
\hline & $x_{1}^{1}(\cdot)=1$ & $x_{2}^{1}(\cdot)=1$ & $x_{3}^{1}(\cdot)=0.1$ \\
$\Theta=\{0.3,0.3,0.3\}$ & $T_{1}=-0.12$ & $T_{2}=0.09$ & $T_{3}=0.03$ \\
\hline
\end{tabular}

Table 1: Investment and Transfers for Different Levels of Liquidity Shocks

In the full enforcement case, the level of investment depends on the amount of transfers that can be extracted from island 1 - the only island where $\pi_{i} R>1$ - and the subsidy required to support investment on islands 2 and 3. As illustrated in Proposition 2., this is not a general property but results from the fact that the aggregate liquidity shocks $\left(\sum_{i=1}^{3} \theta_{i} \leq 0.9\right)$ are not high enough to interfere with the optimal transfer schedule. Hence, for this example, aggregate investment remains the same for all three levels of the liquidity shock considered.

As can be seen from Table 1, the investment levels for the no inter-island enforcement case depend upon the level of liquidity shocks. In the absence of liquidity shocks $(a=0)$, there is no interbank insurance. As a result, no investment occurs on islands 2 and 3 , leading to lower aggregate investment. As liquidity shocks increase, the amount of insurance that can be supported also increases. Provided liquidity needs are sufficiently high $(a=0.3)$ the investment allocations implemented in the no-enforcement case are identical to those of the full enforcement case. 
The above example can be easily adapted to illustrate the key role the realized joint distribution plays. Suppose that $\Theta=\{0,0.1,0.3\}$, where the other parameter values remain unchanged. Then, there are $3 !=6$ possible realizations. The allocations and transfers for each of these possible realizations are given in Table 2 below.

\begin{tabular}{|c|c|c|c|}
\hline & $i=1$ & $i=2$ & $i=3$ \\
\hline & $\pi_{1}=0.8$ & $\pi_{2}=0.65$ & $\pi_{3}=0.5$ \\
& $\pi R=1.1 .2$ & $\pi_{2} R=0.91$ & $\pi_{3} R=0.7$ \\
\hline Inter-Island & $x_{1}^{1}(\cdot)=1$ & $x_{2}^{1}(\cdot)=1$ & $x_{3}^{1}(\cdot)=0.1$ \\
Full Enforcement & $T_{1}=-0.12$ & $T_{2}=0.09$ & $T_{3}=0.03$ \\
\hline Inter-Island & & & \\
No Enforcement & & & \\
\hline$\theta_{1}=0, \theta_{2}=0.1, \theta_{3}=0.3$ & $x_{1}^{1}(\cdot)=1$ & $x_{2}^{1}(\cdot)=0$ & $x_{3}^{1}(\cdot)=0$ \\
$\theta_{1}=0, \theta_{2}=0.3, \theta_{3}=0.1$ & $T_{1}=0$ & $T_{2}=0$ & $T_{3}=0$ \\
\hline$\theta_{1}=0.1, \theta_{2}=0, \theta_{3}=0.3$ & $x_{1}^{1}(\cdot)=1$ & $x_{2}^{1}(\cdot)=0.44$ & $x_{3}^{1}(\cdot)=0$ \\
$\theta_{1}=0.1, \theta_{2}=0.3, \theta_{3}=0$ & $T_{1}=-0.04$ & $T_{2}=0.04$ & $T_{3}=0$ \\
\hline$\theta_{1}=0.3, \theta_{2}=0.1, \theta_{3}=0$ & $x_{1}^{1}(\cdot)=1$ & $x_{2}^{1}(\cdot)=1$ & $x_{3}^{1}(\cdot)=0.1$ \\
$\theta_{1}=0.3, \theta_{2}=0, \theta_{3}=0.1$ & $T_{1}=-0.12$ & $T_{2}=0.09$ & $T_{3}=0.04$ \\
\hline
\end{tabular}

Table 2: Investment and Transfers for Different Joint Distributions and $\Theta=\{0,0.1,0.3\}$

With full enforcement between islands the joint distribution of liquidity and asset shocks is irrelevant. With limited enforcement, however, the overall level of investment depends upon the joint distribution. In this example, the liquidity shock realized for island 1 the only island from which transfers can potentially be extracted - determines the extent of interbank insurance which in turn determines the amount of investment that can be subsidized on the other islands with bad collateral shocks. The lower liquidity needs are on island 1 , the lower is the threat of exclusion from interbank lending markets and, hence, the lower is the quantity of transfers that can be extracted from island 1 to subsidize projects on other islands. For a specific joint distribution the islands are able to achieve the first-best level of investments, whereas for others they are unable to do so. Thus, islands now face aggregate 
uncertainty that arises endogenously from the fact that the joint distribution matters for overall investment.

\section{Discussion}

The theoretical model analyzed above characterizes optimal interactions between banks. In particular, we illustrate a channel which can induce banks to provide mutual interbank asset insurance in the absence of institutions explicitly guaranteeing enforcement. Specifically, the cost of exclusion from interbank lending markets provides an incentive for banks to coinsure one another in the face of asset shocks. This illustrates our main message that interbank arrangements for asset insurance can be supported by the need for interbank loans to meet stochastic liquidity demands. An interesting feature of these interbank arrangements is that they lead to endogenous aggregate uncertainty, as the level of interbank transfers and hence the level of investment - is dependent upon the realized joint distribution of asset and liquidity shocks.

It is crucial to understand not only how asset and liquidity shocks translate into the particular form of insurance provided among banks, but also why and when these shocks cause banks to fail. Collateral shocks combined with the assumption that projects are inherently "good" imply that insurance can improve welfare by increasing the level of investment. The objective of deposit insurance is then to encourage banks to undertake loans which otherwise would not have been undertaken due to the risk of insolvency. ${ }^{17}$

\footnotetext{
${ }^{17}$ As earlier noted by Kocherlakota (1999), an optimally designed insurance system should be characterized by a positive level of "bank failures" - that is, there should be positive transfers to institutions whose liabilities to depositors exceed the value of assets. This observation also sheds different light on the large payouts made by public deposit insurance systems during the 1980s and 1990s in the U.S. and other countries. In particular, it suggests that these large payments may have been at least partially efficient.
} 
In our framework, potential bank failures are always triggered by the insolvency of banks arising from shocks to their assets and the information depositors receive about it, rather than by random liquidity demand of depositors. ${ }^{18}$ The model, therefore, provides further support for the view that liquidity shocks do not provide a motive for insurance among banks to prevent bank failures. Rather, as pointed out by Chari (1989), a functioning interbank lending system is sufficient to deal with liquidity shocks. The presence of liquidity shocks, nevertheless, plays an important role in our framework. Interbank lending essentially allows for a relocation of deposits from potentially insolvent banks to solvent banks. Solvent banks have to rely on this form of interbank lending to cope with liquidity needs. Therefore, in a situation where insurance payments against asset shocks cannot be enforced explicitly, the need for liquidity provides a counterbalancing force that limits reneging on ex-post insurance transfers.

It is precisely this interaction between the two shocks that can help to explain some of the features of interbank cooperation mentioned earlier in the introduction. In our framework individual banks do not fail due to a bank specific run unless they are insolvent. Other banks will lend to provide liquidity in exchange for asset insurance. Moreover, if the aggregate level of liquidity needs increases, cooperation among banks is facilitated since enforcement problems are mitigated. This implies that interbank cooperation functions best exactly in the case of system wide liquidity crises. To the contrary, an increase in the overall level of

\footnotetext{
${ }^{18}$ There is an increasing empirical and theoretical literature stressing this important distinction and its implications. Empirical studies that confirm the information based theory of bank runs are provided for example by Calomiris and Mason (1997) and Calomiris and Gorton (1991) for bank runs during the Great Depression and by Schumacher (2000) for the crisis of the Argentine banking system in 1995. All these studies are in particular relevant for our context since they cover situations where public regulation and safety nets were absent or very limited, and could, therefore, have potentially given rise to the theory of random liquidity demand.
} 
asset shocks threatens mutual insurance among banks by worsening the commitment problem. Hence, systemic banking crises are always induced through shocks to the banks' assets. These shocks, however, have to occur across all banks in our model to precipitate a system-wide crisis: Asymmetric shocks to only a few banks might limit the amount of insurance provided to these banks, but will not put the cooperation based banking system per se at risk.

Moreover, considering safety net systems, governments can play a crucial role in their efficient design by offsetting enforcement limitations. Our findings also suggest a possible explanation for why government mandated deposit insurance systems have supplanted interbank insurance arrangements in most countries. In light of our model, the explanations are that either asset risk increased or the provision of liquidity needs moved away from interbank lending to anonymous liquidity markets or even central banks, both of which made existing interbank insurance arrangements less effective.

The model here provides a framework which can be extended so as to analyze a number of policy related questions. One such question is linked to bank runs caused by depositors who lack appropriate information concerning the bank's asset portfolio. It would be possible to enrich the model by introducing an assymetry of information between banks and individual lenders, and analyzing whether banks are able to avoid a run via the type of cooperation introduced in this paper. ${ }^{19}$ Obviously, a related question would be the possibility of financial contagion caused by shocks originating on the asset side. Finally, it appears intriguing to incorporate moral hazard with respect to the banks' investment decisions into the model. This extension would permit one to endogenize the choice of banking regulation, weighing

\footnotetext{
${ }^{19}$ Several sources (e.g. Gorton (1985) and Calomiris and Mason (1997)) identify examples that support this view.
} 
the cost and benefits of public regulation against private cooperation.

Several short remarks concerning our theoretical approach are in order. First, the optimal inter-island contract is in general not coalition-proof or - in other words - not enforceable against multi-player deviations. For coalition-proof contracts, the scope of insurance is generally limited, as the "threat point" feature of liquidity needs is partially mitigated. ${ }^{20}$ Second, repeating the environment obviously reduces the enforcement problem among islands. However, unless reputation effects are strong enough, the problem stays qualitatively the same.

\section{Appendix}

\section{Proof of Lemma 1.}

Proof. Setting $\delta_{i}^{V}(s)$ equal to 1 relaxes the borrowers' participation constraints (4) and (5) independently of $x_{i}^{0}$ and $x_{i}^{1}(s)$. Since the collateral good is valued only by borrowers, $\delta_{i}^{V}(s)=1$ for all $i=1, \ldots, N$ is optimal. By hypothesis, the borrowers' participation constraint (4) does, then, not bind for any $x_{i}^{0} \in[0,1]$. Hence, lenders are always able to withdraw their funds at stage $t=1$ after they observe the realization of $\tilde{\pi}_{i}$ and $\tilde{\theta}_{i}$. Since $x_{i}^{0}=1$ initiates the maximum number of potentially profitable projects, the result follows.

\section{Proof of Proposition 1.}

Proof. Since all the constraints of problem $\mathcal{P} 2$ are specified as functions of the state $s$, the problem for island $i$ can be decomposed into a separate problem for each island-specific

\footnotetext{
${ }^{20}$ For example, take all the islands that are liquidated due to liquidity needs and some island $i$ with realization $R \pi_{i}>1$. Suppose further the optimal contract specifies implicitly at least some insurance, which implies that some other island $j$ receives funds that are extracted from island $i$. However, island $i$ could obtain insurance against its liquidity needs from the liquidated islands for an arbitrary small positive fee.
} 
realization of $\tilde{\pi}_{i}$ and $\tilde{\theta}_{i}$. Lemma 1 . implies that constraint 4 does not bind. To satisfy the participation constraint (2), a fraction $\theta_{i}$ of investment has to be withdrawn at stage $t=1$. Thus, $x_{i}^{1}(s) \leq 1-\theta_{i}$, which implies that for $N=1$ equation (7) holds.

By assumption 1., $V>R$ and equation (5) never binds. Let equations (2), (3) and (6) hold with equality. For $N=1$, the feasibility constraint for $t=2$ is then given by

$$
\left(1-\pi_{i}\right) R x_{i}^{1}(s)+\pi_{i} c_{B, i}^{V}(s) \leq R x_{i}^{1}(s)-x_{i}^{1}(s)
$$

or

$$
\pi_{i} c_{B, i}^{V}(s) \leq\left(\pi_{i} R-1\right) x_{i}^{1}(s)
$$

Suppose now that $\pi_{i} R<1$. Then $x_{i}^{1}(s) \in\left(0,1-\theta_{i}\right]$ violates non-negativity of $c_{B, i}^{V}(s)$. Hence, $x_{i}^{1}(s)=0$.

If $\pi_{i} R \geq 1$, every $x_{i}^{1}(s) \in\left[0,1-\theta_{i}\right]$ is feasible. Since the objective function is strictly increasing in $c_{B, i}^{V}(s)$ and $c_{B, i}^{0}(s)$, which are increasing in $x_{i}^{1}(s)$, it is optimal to set $x_{i}^{1}(s)=1-\theta_{i}$.

\section{Proof of Corollary 1.}

Proof. Using the investment levels of Proposition 1., one immediately obtains the consumption allocations from the feasibility and participation constraints.

\section{Proof of Corollary 2.}

Proof. Follows immediately from the investment levels of Proposition 1..

\section{Proof of Proposition 2.}

Proof. By Lemma 1. $\delta_{i}^{V}(s)=1$ and $x_{i}^{0}=1$ for all $i=1, \ldots, N$. 
Let $K \geq L$. To verify feasibility of investment levels, set $c_{L, i}^{t}(s)=1$, for $t=1,2$, $c_{B, i}^{0}(s)=R x_{i}^{1}(s)$ and substitute the investment functions into equations (7) and (8) to obtain (20) $\quad \sum_{i=1}^{N} \theta_{i} \leq K$

and

$\sum_{i=1}^{N}\left[\pi_{i} c_{B, i}^{V}(s)\right]+\sum_{i>K}^{N}\left[\left(1-\pi_{i}\right) R\right]+\sum_{i=1}^{N}\left(1-\theta_{i}\right) \leq \sum_{i>K}^{N} R-\left[\sum_{i=1}^{N} \theta_{i}-K\right]$

Since $E\left(\theta_{i}\right) N=L \leq K$ equation (20) is satisfied and equation (21) can be rewritten as

$$
\sum_{i=1}^{N}\left[\pi_{i} c_{B, i}^{V}(s)\right] \leq \sum_{i>K}^{N}\left[\pi_{i} R-1\right]
$$

The definition of $K$ implies $\sum_{i>K}^{N}\left[\pi_{i} R-1\right]=0$, and, hence, feasibility at $t=2$ is satisfied with $c_{B, i}^{V}(s)=0$ for all $i=1, \ldots, N$.

Next, we have to verify the optimality of the contract. Increasing $c_{B, i}^{V}(s)$ for any $i$ - or reducing $x_{i}^{1}(s)$ for some island $i$ - without increasing investment for some other island reduces total investment, and, hence, also welfare. Let $\epsilon>0$ and define a new investment function by

$$
\tilde{x}_{i}^{1}(s)=\left\{\begin{array}{ll}
1-\epsilon & \text { for some n s.th. } \pi_{n} \geq \pi_{K} \\
\epsilon & \text { for some m s.th. } \pi_{m}<\pi_{K} \\
x_{i}^{1}(s) & \text { otherwise }
\end{array} .\right.
$$

The slack for the resource constraint (7) is unaltered. The RHS of Equation (22) is now given by

$$
\sum_{i>K, \quad}^{N}\left(\pi_{i} R-1\right)+(1-\epsilon)\left(\pi_{n} R-1\right)+\epsilon\left(\pi_{m} R-1\right)<0 .
$$


Hence, for some $i, c_{B, i}^{V}(s)<0$. Therefore, to satisfy feasibility investment has to be reduced further for some island $i$ with $\bar{\pi}>\pi_{i}>\pi_{K}$. This reduces overall investment and, hence, the value of the objective function.

Let $L>K$. Since $\sum_{\{i \mid i>L\}}(\pi R-1)>0$, replacing $\mathrm{K}$ by $\mathrm{L}$ in the case above proves that $N-L$ is the optimal overall investment level. There are many investment functions that can achieve this overall level (for example set $x_{i}^{1}(s)=1$ for all $i$ s.th. $\pi_{i}>\pi_{L}$ ). The only requirement is that investment yields enough surplus - to be extracted from borrowers with valuable collateral - to pay off late lenders.

Total extractable gross return on investment is given by $\sum_{i=1}^{N}\left[\pi_{i} R x_{i}^{1}(s)\right]$. To ensure that $c_{L, i}^{2}(s)=1$ for all $i$, at least $\sum_{i=1}^{N} c_{L, i}^{2}=N-L$ resources have to be provided in extractable net returns. Hence, extractable gross return for every optimal investment has to satisfy

$$
\sum_{i=1}^{N}\left[\pi_{i} R x_{i}^{1}(s)\right] \geq N-L
$$

or

$$
\sum_{i=1}^{N}\left[\pi_{i} R x_{i}^{1}(s)\right]-\sum_{i=1}^{N} x_{i}^{1}(s) \geq 0
$$

Then, equation (25) together with an overall investment level of $N-L$ characterize optimal investment.

\section{Proof of Corollary 3.}

Proof. Let $K \geq L$. Since Proposition 2. has $x_{i}^{1}(s)>1-\theta_{i}$ for all $i$ s.th. $\pi_{i}>\pi_{K}$, we have interbank lending for every optimal inter-island contract. Define

$$
T_{i}(s)= \begin{cases}-\left(\pi_{i} R-1\right) & \text { if } \pi_{i}>\bar{\pi} \\ \left(\pi_{i} R-1\right) & \text { if } \pi_{K} \leq \pi_{i} \leq \bar{\pi} \\ 0 & \text { if } \pi_{i}<\pi_{K}\end{cases}
$$


It follows immediately that this deposit insurance system uniquely implements the investment levels of Proposition 2. for all $i$ s.th. $\bar{\pi}>\pi_{i}>\pi_{K}$.

Let $L>K$. Suppose there exists an optimal contract without interbank lending and without deposit insurance system. Then, by absence of interbank lending, we have $x_{i}^{1}(s) \leq 1-\theta_{i}$ for all $i$. Also, since there is no deposit insurance system, $x_{i}^{1}(s)=0$ for all $i$ s.th. $\pi_{i}<\bar{\pi}$. This implies

$$
\sum_{i=1}^{N} x_{i}^{1}(s)=\sum_{i>L}^{N} x_{i}^{1}(s) \leq \sum_{i>L}^{N}\left(1-\theta_{i}\right)<N-L,
$$

contradicting Proposition 2..

\section{Proof of Corollary 4.}

Proof. Follows immediately from the investment levels of Proposition 2..

\section{Proof of Proposition 3.}

Proof. Lemma 1. applies again. Equation 15 follows then immediately from Proposition 2. since the set of feasible investment functions of problem $\mathcal{P} 1$ is a subset of those of problem P3.

Dependence on the overall level of liquidity needs and the joint distribution are a direct consequence of Propositions 4. and 5. which are proved below.

\section{Proof of Proposition 4.}

Proof. Suppose $K \geq L$. It is clear from Proposition 2. that $x_{i}^{1}(s)=1$ for all $i$ s.th. $\pi_{i} \geq \bar{\pi}$ and $x_{i}^{1}(s)=0$ for all $i$ s.th. $\pi_{i} \leq \pi_{K}$. Since the objective function is increasing in the number of projects funded, it is optimal to fund as many projects on islands with $\pi_{K}<\pi_{i}<\bar{\pi}$ as possible. The possibility of funding projects on these islands depends on the 
maximal amount of transfers that can be extracted from islands with $\pi_{i} \geq \bar{\pi}$. It follows - by an identical argument to that used in the proof of Proposition 2. - that Equation 16 holds with equality for a unique $\tilde{\pi}$ and $\tilde{x}_{i}$.

Suppose $\exists$ some $i$ s.th. $\pi_{i}>\bar{\pi}$ and $\theta_{i}<\frac{\pi_{i} R-1}{R-1}$. Then, for any feasible $\left\{T_{i}\right\}_{i=1}^{N}$,

$$
-T_{i}(s) \leq \theta_{i}(R-1)<\left(\pi_{i} R-1\right)
$$

and

$$
\sum_{i>K}^{N-M}\left(\pi_{i} R-1\right)<\sum_{i>N-M}^{N} T_{i}(s)
$$

Hence, to satisfy Equation 16, $x_{i}^{1}(s)<1$ for some $i$ s.th. $\pi_{K}<\pi_{i}<\bar{\pi}$. Therefore, $\sum_{i=1}^{N} x_{i}^{1}(s)<N-L$.

Conversely, if $\theta_{i} \geq \frac{\pi_{i} R-1}{R-1}$ for all $\pi_{i}>\bar{\pi}$, the transfer scheme of Corollary 3. is feasible and achieves $\sum_{i=1}^{N} x_{i}^{1}(s)=N-L$.

\section{Proof of Proposition 5.}

Proof. To prove part 1 , let $L \geq N-M$. Then, $x_{i}^{1}(s)=1$ for all $i$ with $\pi_{i}>\pi_{L}$ is feasible and optimal, since at least an equivalent of $L$ islands have to be liquidated to satisfy overall liquidity needs. For $N-M>L$, set $x_{i}^{1}(s)=1$ for all $i$ s.th. $\pi_{i} \geq \bar{\pi}$. Since $\sum_{i>N-M}^{N} \bar{T}_{i}(s) \leq \sum_{i>L}^{N-M}\left(\pi_{i} R-1\right)$, by using transfer schemes for these island as specified in Corollary $3 ., x_{i}^{1}(s)=1$ for all $i$ with $\bar{\pi}>\pi_{i}>\pi_{L}$ is feasible. Since $\sum_{i=1}^{N} x_{i}^{1}(s)=N-L$, these investment levels are optimal.

Suppose now that $\left\{x_{i}^{1}(s)\right\}_{i=1}^{N}$ are s.th. $\sum_{i=1}^{N} x_{i}^{1}(s)=N-L$. If condition (17) is satisfied for these investment levels, they are feasible. Since total investment equals $N-L$, they are optimal by the argument given above. 
Part 2 applies only to $N-M>L$, since otherwise the initial restriction of part 2 in the statement of the proposition is meaningless. The proof of uniqueness of the optimal investment functions on individual islands is analogous to the argument used in the proof of Proposition 4.. Again, the amount of investment on islands with $\bar{\pi}>\pi_{i}>\pi_{L}$ depends on the maximal amount of resources that can be transferred to these islands, which is uniquely given by $\sum_{i>N-M}^{N} \bar{T}_{i}(s)$.

Suppose, by way of contradiction, that $\sum_{i=1}^{N} x_{i}^{1}(s)=N-L$. Uniqueness and form of the optimal investment levels implies that $x_{i}^{1}(s)=1$ for all $i$ s.th. $\pi_{i}>\pi_{L}$. To ensure feasibility of these investment levels, there must be a feasible transfer scheme $\left\{T_{i}\right\}_{i=1}^{N}$ s.th.

$$
\sum_{i>N-M}^{N} T_{i}(s) \leq \sum_{i>L}^{N-M}\left(\pi_{i} R-1\right) .
$$

This contradicts the initial condition of part 2 .

Finally, suppose, by way of contradiction, that $\theta_{i}>\frac{\pi_{i} R-1}{R-1}$ for all $\pi_{i}>\bar{\pi}$. Then, by Lemma 2., $\sum_{i>N-M}^{N} \bar{T}_{i}(s) \leq \sum_{i>L}^{N-M}\left(\pi_{i} R-1\right)$. This contradicts the initial condition of part 2 and, hence, the final statement of the proposition follows.

\section{Proof of Corollary 5.}

Proof. Follows from the specification of optimal investment levels given in Proposition 4 . and 5. and the proof of Corollary 3..

\section{Proof of Corollary 6.}

Proof. Follows from the investment levels given in Proposition 4. and 5..

\section{Proof of Corollary 7.}


Proof. The first result is obvious. The second result follows from the fact that $\theta_{i} \geq \frac{\pi_{i} R-1}{R-1}$ for all $\pi_{i}>\bar{\pi}$ implies $\bar{T}_{i}=\pi_{i} R-1$ for all $i$ s.th. $\pi_{i} \geq \bar{\pi}$.

\section{References}

Allen F. and Gale, D. (2000). Financial Contagion, Journal of Political Economy, Vol. 108, No. 1, pp. 1-33.

Bhattacharya, S. and Gale, D. (1987). Preference Shocks, Liquidity, and Central Bank Policy, in New Approaches to Monetary Theory, W.A. Barnett and J. Singleton (eds.), New York, Cambridge University Press, pp. 69-88.

Bhattacharya, S. and Fulghieri, P. (1994). Uncertain Liquidity and Interbank Contracting, Economics Letters, Vol. 44, pp.287-294.

Bryant, J. (1980). A Model of Reserves, Bank Runs, and Deposit Insurance, Journal of Banking and Finance, Vol. 4, pp. 335-344.

Calomiris, C.W. (1990). Is Deposit Insurance Necessary: A Historical Persepctive, The Journal of Economic History, Vol. 50, pp. 283-295.

Calomiris, C.W. and Gorton, G. (1991). The Origin of Banking Panics: Models, Facts and Bank Regulation, in Financial Markets and Financial Crises, R.G. Hubbard (ed.), University of Chicago Press, pp. 109-175.

Calomiris, C.W. and Kahn C.M. (1991). The Role of Demandable Debt in structuring Optimal Banking Arrangements, American Economic Review, Vol. 81, No. 3, pp. 497-513.

Calomiris, C.W. and Mason, J.R. (1997). Contagion and Bank Failures During the Great Depression: The June 1932 Chicago Banking Panic, American Economic Review, Vol. 87 No. 5, pp. 863-883.

Chari, V.V. (1989). Banking Without Deposit Insurance or Bank Panics: Lessons From a Model of the U.S. National Banking System, Federal Reserve Bank of Minneapolis Quarterly Review, Vol. 13, No. 3.

Diamond, D.W. and Dybvig, P.H. (1983). Bank Runs, Deposit Insurance, and Liquidity, Journal of Political Economy, Vol. 91, No. 3, pp. 401-419.

English, W. (1993). The Decline of Private Deposit Insurance in the United States: CarnegieRochester Conference Series on Public Policy, Vol. 38, pp. 57-128.

Freixas, X., Parigi, B. and Rochet, J. (1998). Systemic Risk, Interbank Relations and Liquidity Provision by the Central Bank, mimeo, Universitat Pompeu Fabra.

Gorton, G. (1985). Clearinghouses and the Origin of Central Banking in the United States The Journal of Economic History, Vol. 45 pp. 277-283.

Kocherlakota, N. (1999). Risky Collateral and Deposit Insurance, mimeo, University of Minnesota. 
Rochet J. and Tirole J. (1996). Interbank lending and Systemic Risk, Journal of Money, Credit and Banking, Vol. 28, Issue 4, part 2, pp. 733-762.

Schumacher, L. (2000), Bank Runs and Currency Run in a System Without a Safety-Net: Argentina and the Tequila Shock, Journal of Monetary Economics, Vol. 46, pp. 257-277.

Williamson, S.D. (1989). Bank Failures, Financial Restrictions, and Aggregate Fluctuations: Canada and the United States, 1870-1913, Federal Reserve Bank of Minneapolis Quarterly Review, Vol. 13, No. 3. 

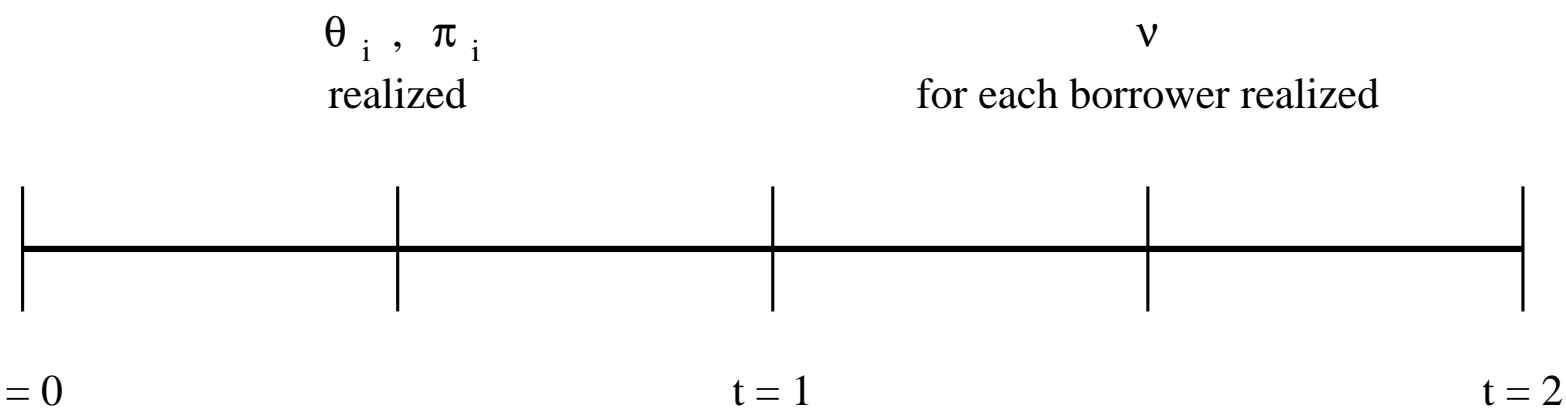

Contracting

Island as a whole decides

to walk away

Lenders withdraw funds if possible

Early lenders consume
Project return $\mathrm{R}$ realized

Borrowers on each island decide to walk away

Borrowers and late lenders consume 